\title{
Why the move to microfluidics for protein analysis? Niels Lion ${ }^{1}$, Frédéric Reymond ${ }^{2}$, Hubert H Girault ${ }^{1}$ and Joël S Rossier ${ }^{2 *}$
}

\begin{abstract}
There has been a recent trend towards the miniaturization of analytical tools, but what are the advantages of microfluidic devices and when is their use appropriate? Recent advances in the field of micro-analytical systems can be classified according to instrument performance (which refers here to the desired property of the analytical tool of interest) and two important features specifically related to miniaturisation, namely reduction of the sample volume and the time-to-result. Here we discuss the contribution of these different parameters and aim to highlight the factors of choice in the development and use of microfluidic devices dedicated to protein analysis.
\end{abstract}

\author{
Addresses \\ ${ }^{1}$ Laboratoire d'Electrochimie Physique et Analytique, Ecole \\ Polytechnique Fédérale de Lausanne, $\mathrm{CH}-1015$ Lausanne, Switzerland \\ ${ }^{2}$ DiagnoSwiss SA, Route de l'lle au Bois 2, CH-1870 Monthey, \\ Switzerland \\ *e-mail: j.rossier@diagnoswiss.com
}

Current Opinion in Biotechnology 2004, 15:31-37

This review comes from a themed issue on

Analytical biotechnology

Edited by Keith Rose

0958-1669/\$ - see front matter

(c) 2004 Elsevier Ltd. All rights reserved.

DOI 10.1016/j.copbio.2004.01.001

$\begin{array}{ll}\text { Abbreviations } \\ \text { CE } & \text { capillary electrophoresis } \\ \text { 2D-GE } & \text { two-dimensional gel electrophoresis } \\ \text { ECD } & \text { electron capture dissociation } \\ \text { ESI-MS } & \text { electrospray ionization mass spectrometry } \\ \text { MALDI-MS } & \text { matrix-assisted laser desorption ionization mass } \\ & \text { spectrometry } \\ \text { MS } & \text { mass spectrometry } \\ \text { SPE } & \text { solid phase extraction }\end{array}$

\section{Introduction}

Microfluidic (bio)analytical devices have received much interest over the past 15 years, mainly because of the advent of large-scale biology, namely genomics and proteomics. These requirements include extreme sensitivity and reproducibility, high-throughput and the need to derive a wide variety of relevant structural or biochemical information (see [ $\left.1^{\circ}\right]$ for further details and an extensive review on protein microsystems). The motivations for turning from macroscale analytical procedures to microanalytical devices is variously defined in the literature as a low sample consumption, fast analysis times and highthroughput potentialities, the possibility of integration and automation, and the desire for single-use devices associated with the suppression of cross-contamination.
These four major driving forces are rarely precisely defined, however, and the purpose of this review is to further understanding of the benefits that can be obtained from miniaturization. In particular, decreased sample volume and time reduction are not always attainable simultaneously, or even desirable, although this is claimed to be the case by many authors. Why move towards the use of microfluidic bio-analytical devices and which technical solutions should be adopted for a particular problem? We propose to tackle these questions by analysis of the analytical triangle: performance (i.e. the desired analytical performance which is a prerequisite of any analytical tool), sample volume and time-to-result, which are more intrinsically linked to microfluidics. Recent examples from the literature are analyzed in the light of this triangle, with a special focus on protein microfluidic systems (microarrays are not discussed here).

\section{The analytical triangle}

Performance refers herein to the expected result, depending on the particular problem to be solved. As such, performance is a function of different parameters, for example, detection limit, selectivity, reproducibility, the ability to repeat an assay, analysis time and sample volume. Depending on the application, the analytical platform will not seek the same performance. Reduction of sample volume and, often, reduction of the time-to-result are intrinsically linked to miniaturization. In the choice of an analytical platform, it is therefore compulsory to understand how these two parameters impact the performance of the entire platform. For this reason, these two items are explicitly differentiated in the present report.

The case for sample volume is quite obvious, and it may always seem desirable to reduce the sample volume as far as possible to save precious chemicals or to limit clinical sampling (e.g. for the analysis of cerebrospinal fluid or for neo-natal testing). However, in the case of in vitro diagnostics, a few milliliters of blood are usually withdrawn for sampling, so reducing the sample size to submicroliters is unlikely to be the major driving force in the development of a miniaturized assay. On the contrary, minimizing the amount of sample may be the primary goal of assay development in some instances; for example, in the case of in vivo glucose sensing, where diabetic patients are tested several times a day, to reduce sampling pain Therasense Inc. developed a portable sensor that samples volumes as small as $0.3 \mu \mathrm{l}$ [2].

The other factor that is generally emphasized in the miniaturization of analytical tools is the reduction of time taken to obtain the result (time-to-result). The principle 
Figure 1

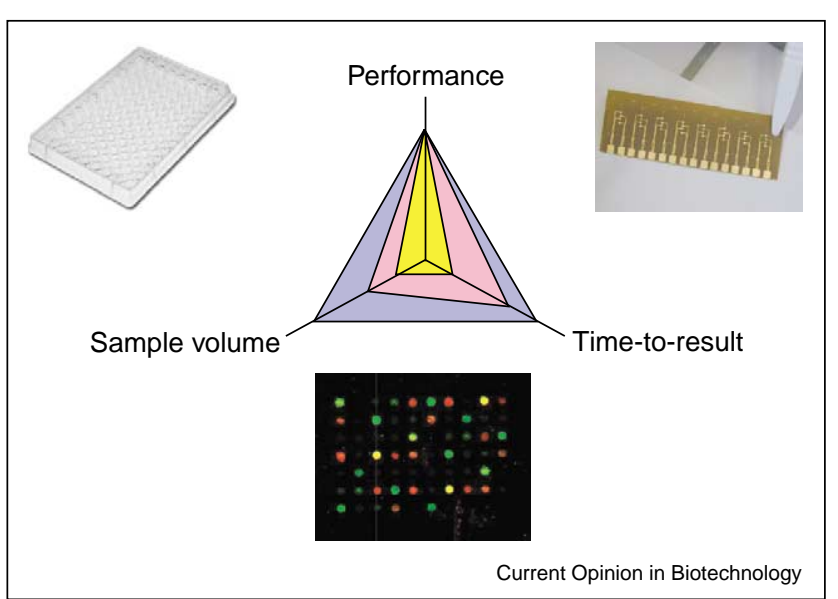

A comparison of the different bioanalytical tools in the framework of the analytical triangle: performance, time-to-result and sample volume. An immunoassay in a microtiter plate requires several hours with a relatively large amount of sample (purple surface in the graph), a microarray requires less sample, but a relatively long incubation time (pink surface in the graph), and a microfluidic immunoassay deals with small volumes and is completed in a few minutes (yellow surface in the graph). This figure shows an example of each of the above-described analytical platforms, namely (from left to right) a polystyrene microtiter plate from Beckman Coulter Inc. (Fullerton, USA), a microdot array from Haab et al. [46], and a polyimide microchip with integrated gold electrodes from DiagnoSwiss SA (Monthey, Switzerland).

here is also quite simple and argues that two molecules placed in a large volume will take more time to contact each other (and further react) than if placed in a very small, confined environment. This feature does not change the kinetics of the reaction, but reduces the mass transport time from typically $1 \mathrm{~h}$ in the mesoscale world (microtiterplate well) to a few seconds in a microchannel with a typical dimension of $50 \mu \mathrm{m}$. The same philosophy can be applied to separation, where a smaller scale reduces the separation time. (It should be stressed here that one should not confuse time-to-result with highthroughput, which can be achieved by parallelization of most of the analytical processes.) To further illustrate the concept of this analytical triangle, Figure 1 delineates how a microtiter plate, a microarray and a microfluidic immunoassay would compare to reach the performance desired in the different assays: the microtiter plate deals with large amounts of sample (in the milliliter range) and requires relatively long incubation times (in the hour range). Comparatively, the microarray is incubated with a few tens of microliters for a relatively long time, whereas the microfluidic immunoassay requires only a few microliters of sample and is completed in a few minutes [3].

The impact of the sample volume and time-to-result on the performance of a micro-analytical system is discussed in more detail below, with reference to recent advances in microfluidics.

\section{Sample volume reduction}

When thinking of microfluidics, the first feature to come to mind is small volumes. The outstanding surface-tovolume ratio of microchannels (typically $80000 \mathrm{~m}^{-1} \mathrm{com}-$ pared with $500 \mathrm{~m}^{-1}$ for a microtiter plate well) allows elution of samples in incomparably small volumes after capture on a solid-phase extraction (SPE) sorbent [4,5] (see Figure 2). Yu et al. further increased the intrinsically high surface-to-volume ratio of their microfluidic device by incorporating a monolith within the microchannel [6]; by eluting green fluorescent protein in a very small volume they were able to reach 1000 -fold preconcentration [7].

In some analyses only very small volumes of samples are directly available, or samples might come from an upstream sample preparation step that resulted in a

\section{Figure 2}

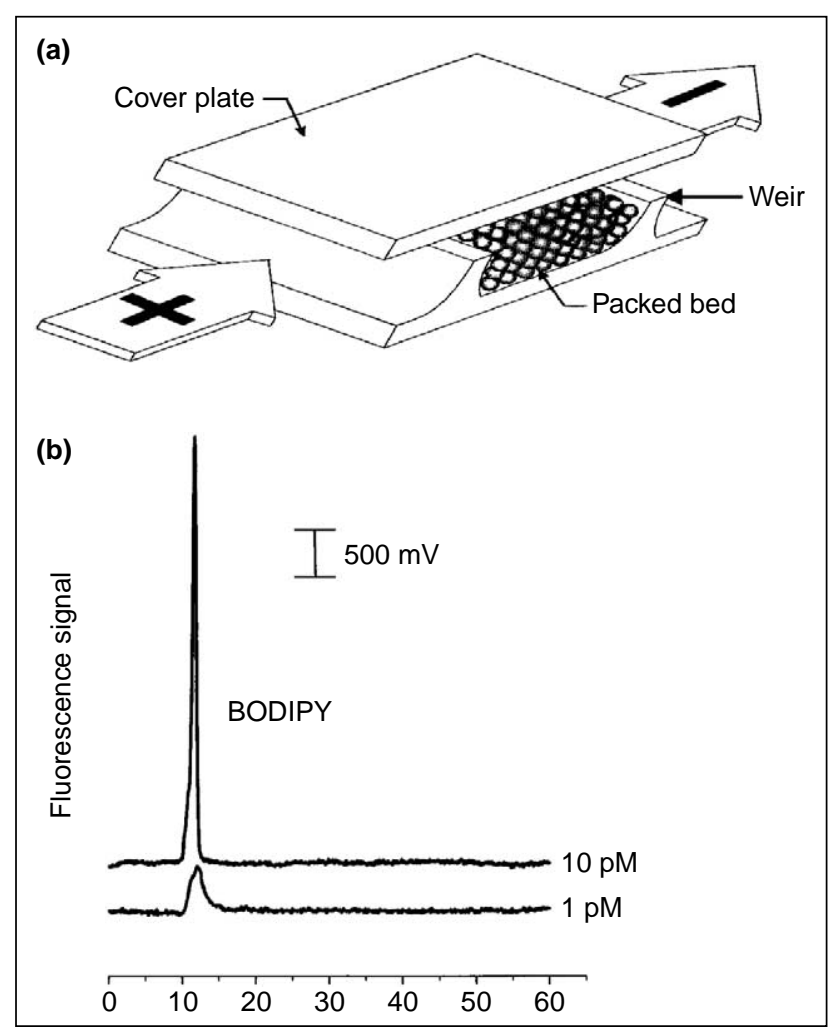

SPE microdevice for protein digest analysis. (a) Isometric projection of the packed bed used for SPE and capillary electrochromatography (CEC) illustrating the $1 \mu \mathrm{m}$ deep weirs used to trap the bead bed.

The volume of the chamber is $330 \mathrm{pL}$, which enables preconcentration of extremely small sample volumes. (b) Elution trace of $1 \mathrm{pM}$ of a fluorescent dye, BODIPY $(\mathrm{S} / \mathrm{N}=45)$ and $10 \mathrm{pM}$ BODIPY $(\mathrm{S} / \mathrm{N}=434)$, obtained after concentration for $3 \mathrm{~min}$ from $\mathrm{pH} 8.3$ aqueous buffer from the SPE bed depicted in (a). Elution was performed with $40 \%$ acetonitrile/60\% pH 8.3 buffer. (Figure reproduced from [5] with permission.) 
concentrated small volume. Thus, miniaturization appears as a valuable alternative to dilution, which would be necessary to analyze the sample in the macro-world. Scaling down an analytical process poses technical problems, however, and these have been reviewed from a general view point by Madou and Cubicciotti $\left[8^{\bullet}\right]$. Matching sample volume and the sensitivity of the chosen detection technique is a crucial point that is further discussed by Lion et al. $\left[1^{\bullet}\right]$ in the context of protein analysis and proteomics. It is not the scope of this paper to enter into the specificities of each detection technique, and the reader is referred to these two reviews for further details. Nevertheless, miniaturization of analytical tools has been undertaken for many years without microfabrication technologies. The development of pulled capillary nanospray emitters for peptide and protein analysis by electrospray ionization mass spectrometry (ESI-MS) allowed the routine analysis of a few microliters [9]. These devices are now being microfabricated with technologies imported from the microelectronics industry to improve reproducibility and robustness of the system. Many technological approaches have been based on polymer [10-13] and glass or silicon [14,15] microfabrication, among them are mature devices working either with robotic stations such as the Nanomate ${ }^{\mathrm{TM}}$ system from Advion Biosciences [16 ${ }^{\bullet \bullet}$ or stand-alone disposable devices [17]. This kind of micro- or nanospray microfabricated emitter is appearing at a time when exciting developments in mass spectrometry are starting to emerge, such as new methodologies based on the capabilities of MS for the structural elucidation of protein complexes or complex mixture analysis. For example, Kalkum et al. [18] recently introduced a methodology called 'hypothesis-driven multistage mass spectrometry' to assess the presence of particular compounds in a mixture: peptides of an expected mass are very selectively isolated by tandem mass spectrometry (MS/MS) and their identification further confirmed by MS/MS/MS (where the third mass stage is used to fragment the isolated molecules and further confirm their identity). No previous separation is required. Using this approach, more than one hundred secreted peptides were interrogated in a single MS experiment from direct cell culture supernatant. Although the proof-of-principle for this methodology was presented with matrix-assisted laser desorption ionization MS (MALDI-MS), there is no fundamental reason why it could not be extended to ESI-MS. Similarly, Emmett [19] presented MS/MS/ MS developments in Fourier transform ion cyclotron resonance MS (FTICR-MS) for the elucidation of the glycosylation structure on proteins separated by twodimensional gel electrophoresis (2D-GE). Different fragmentation processes, namely electron capture dissociation (ECD) and infrared multiphoton dissociation (IRMPD), were combined to obtain complementary information about tryptic peptide sequences and carbohydrate structure.
These two examples are typical of the progress made in MS technology during the past few years: more and more information can be gathered during a single experiment at the cost of analysis time. Most of these technologies cannot be operated at the pace of a liquid chromatograph, so it is necessary to handle small samples (typically less than $2 \mu \mathrm{l}$ ) during long analysis times with reliable possibilities of re-interrogation (which implies better robustness and reproducibility than current nanospray needles). For this kind of methodology, microchips (e.g. thin polymer infusion microtips [17]) seem a particularly valuable option, as they can combine small sample volumes with high-performance results and flexible experimental times.

One issue when dealing with small volumes is reproducibility: even if 1-2 $\mu$ l can easily be handled manually, microfluidics can help satisfactory reproducibility to be obtained in complex sample preparation. Gyros developed a compact disc (CD)-like platform to prepare peptide digests for MALDI-MS: samples are moved along the sample preparation chain just by rotating the CD. The samples undergo adsorption on a reverse-phase followed by washing out of salts, mixing with the matrix and finally co-crystallization in the outlets of the device. The integration of all steps leads to a very reproducible results [20].

Microfluidics has also been incorporated into BIAcore ${ }^{\mathrm{TM}}$ instruments for measuring surface plasmon resonance, mainly to take advantage of the very well-controlled mass transport phenomena that occur in microdimensions [21], but also limit sample consumption. (It should be noted, however, that surface plasmon resonance is sensitive only to the quantity of mass adsorbed at the surface, not to the concentration of the sample, so downsizing poses sensitivity problems). Microfluidics also allows a controlled recovery of captured analytes for further characterization, for example, by MS [22,23]. For a given sample volume, microsystems can thus increase the performance of an analytical platform by improving the quality and variety of information that can be delivered per assay.

\section{Time-to-result decrease}

It was soon recognized that miniaturization could directly result in a speeding-up of analytical processes, culminating in a report by Jacobson et al. [24] in which submillisecond separation of fluorescent dyes was achieved by on-chip capillary electrophoresis. In the proteomics analytical chain, one of the first limiting steps is proteolysis, which typically requires anything from $4-12 \mathrm{~h}$. Peterson et al. [25] presented a microfluidic system with embedded trypsin immobilized on a monolith, which could reach a sample throughput of one protein digested and analyzed by on-line ESI-MS per minute (see Update). Protein and peptide mixtures must be separated to obtain protein identification within such mixtures. Transfer of capillary 


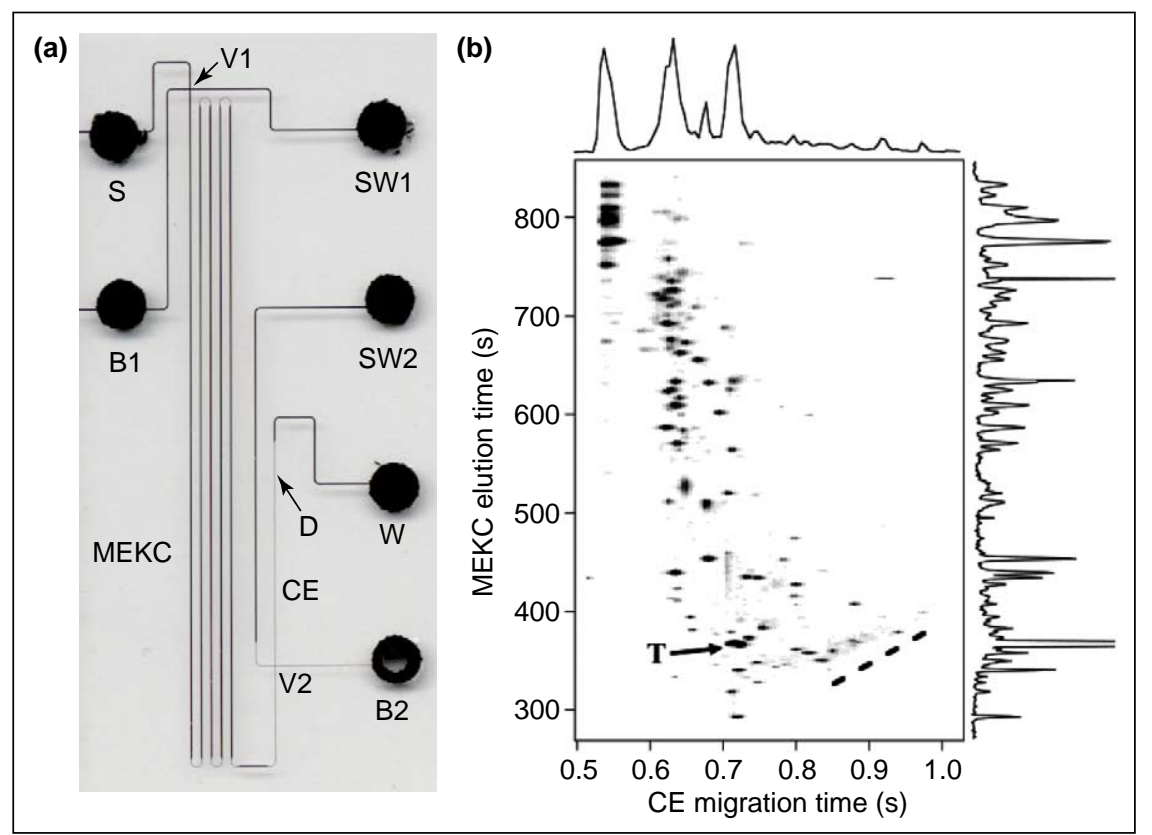

Two-dimensional separation of a protein digest on a chip by micellar electrokinetic chromatography (MEKC) and capillary electrophoresis (CE), which reached a 4200 peak capacity within $15 \mathrm{~min}$. (Figure reproduced from [27*0] with permission.)

gel electrophoresis (CGE) into microfluidic format has also been accomplished by Bousse et al. [26], allowing complete separations within a few minutes. Over the past three years Ramsey's laboratory have pioneered on-chip multidimensional separations $\left[27^{\bullet \bullet}, 28,29\right]$, finally achieving protein digest separations within 15 min with an impressive peak capacity of 4200 (as shown in Figure 3). These separations were accomplished with fluorescent detection only, and allowed the discrimination of bovine and human hemoglobin based on protein digestion fingerprinting.

The coupling of microchips with ESI-MS discussed previously can also result in a decrease in time-to-result: by integration of robotics for sample delivery to the microfabricated electrospray emitter and nozzle-to-nozzle reproducibility provided by microfabrication, the ESIChip ${ }^{\mathrm{TM}}$ from Advion Biosciences provides new tools for MS screening. For instance, Kapron et al. [30] identified and quantified small drugs directly from human plasma with very limited sample preparation at a rate of 60 samples per hour. Likewise, van Pelt et al. [31] demonstrated the screening of drug permeation properties from Caco-2 cell tests with an analysis rate of $45 \mathrm{sec}-$ onds per sample. In both of these examples the new MS microchip allowed complete suppression of a liquid chromatography step and, as such, the time-to-result delay was greatly reduced. From the above-mentioned examples of the use of MS microchips, it can be seen that they can be used either for their intrinsically small sample volume or for reduced time-to-results. In fact, this consideration has a strong impact on the design of the microchip: whereas the integration of one hundred ESI emitters on the same chip with automated sample delivery results in high-throughput capabilities, its cost prevents its use where reduced sample volume without the need for high-throughput is the driving force for miniaturization.

Another field where the time-to-result is crucial is that of clinical immunoassay: several approaches have been presented, such as homogeneous immunoassays with antibody-antigen complex detection and quantification by capillary electrophoresis (CE) and laser-induced fluorescence or electrochemical means [32,33]. By contrast, heterogeneous immunoassays replace CE with a washing step and have been demonstrated on microchip platforms $\left[34^{\bullet}, 35-40\right]$. The key advantage of microfluidics in this case is to bring antibodies and antigens in such close proximity that diffusion is no longer a limiting factor: Rossier et al. [41] showed that depletion of the whole microchannel volume occurred in less than $5 \mathrm{~min}$. Moreover, heterogeneous immunoassays allow the concentration of captured antigen by flowing the sample solution over the antibody bed in an efficient fashion. Picomolar sensitivity with electrochemical detection, fast analysis times of less than $15 \mathrm{~min}$ for the whole immunoassay, and mass production possibilities make this kind of microfluidic immunoassay a very promising tool in diagnostics and protein analysis. In reference to 


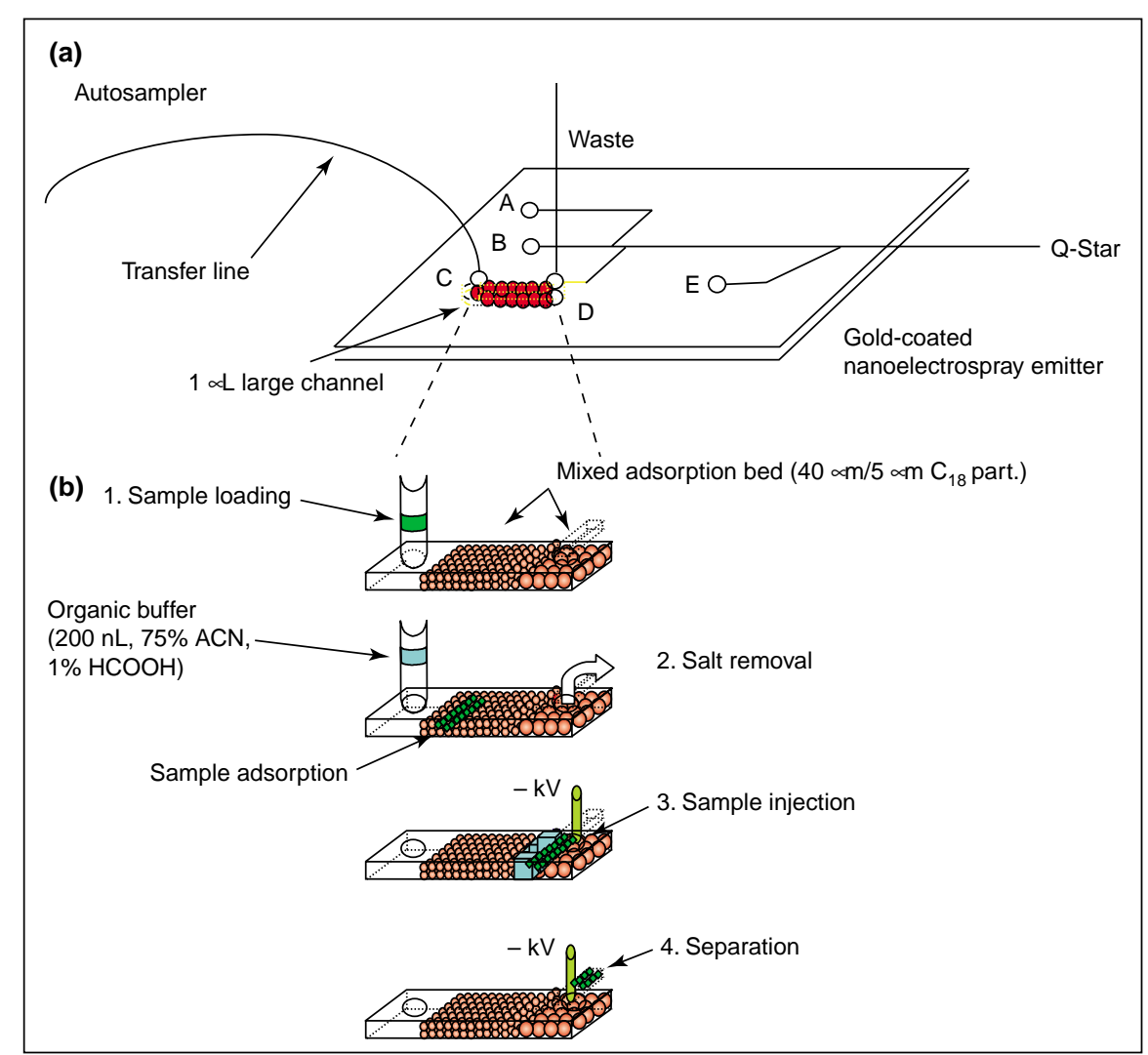

Integrated platforms for protein analysis. (a) Scheme of the device proposed by Li et al. [43*0] for SPE-CE-MS of tryptic digests and (b) the scheme of operation. This device was used for the unattended identification of 72 proteins from a human prostatic cancer cell line LNCap at a rate of 12 samples per hour. (Figure reproduced from $\left[43^{\circ} \cdot\right]$ with permission.)

the above-mentioned analytical triangle the scheme presented in Figure 1 for the microchip-based immunoassay shows that this kind of analytical platform meets best with the requirements of clinical diagnostics. In this domain, the specific features of miniaturization have many advantages, but efforts still need to be made in the industrialization of global microfluidic immunoassay platforms before market implementation.

All these efforts to minimize the volume and time-toresult have resulted in some integrated platforms for protein analysis [42]. One of the most successful to date has been provided by Li et al. $\left[43^{\bullet \bullet}\right]$ who presented the SPE of tryptic digests from 2D-GE followed by CE and infusion to ESI-MS. The design of the device and the scheme of operation are shown in Figure 4. The set-up provided an analysis rate of 12 samples per hour.

\section{Microfluidics in real life}

As briefly presented above, and more extensively reviewed elsewhere $\left[1^{\bullet}, 44^{\bullet}\right]$, many demonstrations of the potentialities of miniaturization for protein analysis have been provided. However, the driving forces for miniaturization are not always clearly outlined, which makes it difficult for potential end-users to identify a clear benefit for their particular application. Although benefits are quite clear in some fields, such as diagnostics where time-to-result can be a matter of survival as for D-Dimer testing $\left[34^{\circ}\right]$, in many other fields microfluidics has not yet been identified as a clear breakthrough. For example, most proteomic or screening laboratories rely on old technologies such as 2D-GE [45] and perceive microfluidics as a disruptive technology that aims to replace all traditional analytical methods. Instead, we believe that microfluidics offers some clear advantages for some analytical applications where very limited amounts of sample are available or where time-to-result is critical. It is probable that clear clinical examples will appear soon, as with the analysis of $2 \mu \mathrm{l}$ of cerebrospinal fluid on a chip, which is hardly feasible with conventional tools.

One should only turn to microfluidics, however, when there is a clear benefit for doing so, because these new technologies are not so easy to operate, often expensive and constitute a change in habits of personnel. It is our 
belief that customers and end-users will continue to segment the microfluidics domain by choosing the types of device that are beneficial for them and that will remain smart academic demonstrations of know-how.

\section{Update}

Peterson et al. [47] recently presented a dual-function microfluidic device for on-line tryptic digestion on a $40 \mathrm{~nL}$ trypsin bed and preconcentration of peptides on a $10 \mathrm{~nL}$ SPE bed. In all experiments, protein digestion was completed in $1 \mathrm{~min}$, and peptides further desalted and concentrated on the SPE bed. No further throughput improvement was obtained from previous studies, but results quality was greatly improved in terms of sequence coverage thanks to the concentration step.

\section{Acknowledgements}

The authors thank the Office Fédéral de l'Education et de la Science of Switzerland for financial funding (OFES grant No. 01.018 in relation with the European Commission grant No. QLG2-CT-2001-01903).

\section{References and recommended reading}

Papers of particular interest, published within the annual period of review, have been highlighted as:

- of special interest

$\bullet$ of outstanding interest

1. Lion N, Rohner TC, Dayon L, Arnaud IL, Damoc E, Youhnovski N,

- Wu ZY, Roussel C, Josserand J, Jensen H et al.: Microfluidic systems in proteomics. Electrophoresis 2003, 24:3533-3562.

This review provides a comprehensive overview of microfluidic developments for protein analysis and proteomics.

2. Chen T, Schmidtke DW, Heller A: Defining the period of recovery of the glucose concentration after its local perturbation by the implantation of a miniature sensor. Clin Chem Lab Med 2002, 40:786-789.

3. Rossier J, Reymond F, Michel P: Polymer microfluidic chips for electrochemical and biochemical analyses. Electrophoresis 2002, 23:858-867.

4. Oleschuk RD, Shultz-Lockyear LL, Ning Y, Harrison DJ: Trapping of bead-based reagents within microfluidic systems: on-chip solid-phase extraction and electrochromatography. Anal Chem 2000, 72:585-590.

5. Jemere AB, Oleschuk RD, Ouchen F, Fajuyigbe F, Harrison DJ: An integrated solid-phase extraction system for sub-picomolar detection. Electrophoresis 2002, 23:3537-3544.

6. Yu C, Davey MH, Svec F, Frechet JMJ: Monolithic porous polymer for on-chip solid-phase extraction and preconcentration prepared by photoinitiated in situ polymerization within a microfluidic device. Anal Chem 2001, 73:5088-5096.

7. Yu C, Xu MC, Svec F, Frechet JMJ: Preparation of monolithic polymers with controlled porous properties for microfluidic chip applications using photoinitiated free-radical polymerization. J Polym Sci [A1] 2002, 40:755-769.

8. Madou MJ, Cubicciotti R: Scaling issues in chemical and - biological sensors. Proc IEEE 2003, 91:830-838.

This review describes scaling problems when trying to match physicochemical properties of fluid handling in microdimensions with conventional macrodevices and detectors. Although very general, it addresses fundamental issues that are hardly evoked in the literature.

9. Wilm M, Mann M: Analytical properties of the nanoelectrospray ion source. Anal Chem 1996, 68:1-8.

10. Kim JS, Knapp DR: Microfabricated PDMS multichannel emitter for electrospray ionization mass spectrometry. J Am Soc Mass Spectrom 2001, 12:463-469.
11. Rohner TC, Rossier JS, Girault HH: On-line electrochemical tagging of cysteines in proteins during nanospray. Electrochem Commun 2002, 4:695-700.

12. Lion N, Gellon JO, Jensen H, Girault HH: On-chip protein sample desalting and preparation for direct-coupling with electrospray ionization mass spectrometry. J Chromatogr A 2003, 1003:11-19.

13. Svedberg M, Pettersson A, Nilsson S, Bergquist J, Nyholm L, Nikolajeff F, Markides K: Sheathless electrospray from polymer microchips. Anal Chem 2003, 75:3934-3940.

14. Sjodahl J, Melin J, Griss P, Emmer A, Stemme G, Roeraade J: Characterization of micromachined hollow tips for twodimensional nanoelectrospray mass spectrometry. Rapid Commun Mass Spectrom 2003, 17:337-341.

15. Griss P, Melin J, Sjodahl J, Roeraade J, Stemme G: Development of micromachined hollow tips for protein analysis based on nanoelectrospray ionization mass spectrometry. J Micromechanics Microeng 2002, 12:682-687.

16. Schultz GA, Corso TN, Prosser SJ, Zhang S: A fully integrated - monolithic microchip electrospray device for mass spectrometry. Anal Chem 2000, 72:4058-4063.

This paper is one of the first descriptions of the ESI-Chip ${ }^{\mathrm{TM}}$ from Advion Biosciences, which constitute a real breakthrough in mass spectrometric protein analysis.

17. Rossier JS, Youhnovski N, Lion N, Damoc E, Reymond F, Girault HH, Przybylski M: Thin-chip microspray system for coupling with high performance Fourier-transform ion cyclotron resonance mass spectrometry. Angew Chem Int Ed Engl 2003, 42:53-58.

18. Kalkum M, Lyon GJ, Chait BT: Detection of secreted peptides by using hypothesis-driven multistage mass spectrometry. Proc Natl Acad Sci USA 2003, 100:2795-2800.

19. Emmett MR: Determination of post-translational modifications of proteins by high-sensitivity, high-resolution Fourier transform ion cyclotron resonance mass spectrometry. $J$ Chromatogr A 2003, 1013:203-213.

20. Ehrnstrom R: Miniaturization and integration: challenges and breakthroughs in microfluidics. Lab on a Chip 2002, 2:26N-30N.

21. Quinn JG, O’Kennedy R: Biosensor-based estimation of kinetic and equilibrium constants. Anal Biochem 2001, 290:36-46.

22. Sonksen $\mathrm{CP}$, Roepstorff $\mathrm{P}$, Markgren $\mathrm{PO}$, Danielson $\mathrm{UH}$, Hamalainen MD, Jansson $\mathrm{O}$ : Capture and analysis of low molecular weight ligands by surface plasmon resonance combined with mass spectrometry. Eur J Mass Spectrom 2001, 7:385-391.

23. Natsume T, Nakayama $H$, Isobe T: BIA-MS-MS: biomolecular, interaction analysis for functional proteomics. Trends Biotechnol 2001, 19:S28-S33.

24. Jacobson SC, Culbertson CT, Daler JE, Ramsey JM: Microchip structures for submillisecond electrophoresis. Anal Chem 1998, 70:3476-3480.

25. Peterson DS, Rohr T, Svec F, Frechet JMJ: High-throughput peptide mass mapping using a microdevice containing trypsin immobilized on a porous polymer monolith coupled to MALDI TOF and ESI TOF mass spectrometers. J Proteome Res 2002, 1:563-568.

26. Bousse L, Mouradian S, Minalla A, Yee H, Williams K, Dubrow R: Protein sizing on a microchip. Anal Chem 2001, 73:1207-1212.

27. Ramsey JD, Jacobson SC, Culbertson CT, Ramsey JM: High-• efficiency, two-dimensional separations of protein digests on microfluidic devices. Anal Chem 2003, 75:3758-3764.

The authors have demonstrated hyphenation of micellar electrokinetic chromatography and capillary electrophoresis on-chip for fast separation of protein digests, with an impressive peak capacity of 4200 . Although achieved with fluorescent detection only, this study demonstrates the power of on-chip separations.

28. Gottschlich N, Jacobson SC, Culbertson CT, Ramsey JM: Twodimensional electrochromatography/capillary electrophoresis on a microchip. Anal Chem 2001, 73:2669-2674. 
29. Rocklin RD, Ramsey RS, Ramsey JM: A microfabricated fluidic device for performing two-dimensional liquid-phase separations. Anal Chem 2000, 72:5244-5249.

30. Kapron JT, Pace E, Van Pelt CK, Henion J: Quantitation of midazolam in human plasma by automated chip-based infusion nanoelectrospray tandem mass spectrometry. Rapid Commun Mass Spectrom 2003, 17:2019-2026.

31. Van Pelt CK, Zhang S, Fung E, Chu IH, Liu TT, Li C, Korfmacher WA, Henion J: A fully automated nanoelectrospray tandem mass spectrometric method for analysis of Caco-2 samples. Rapid Commun Mass Spectrom 2003, 17:1573-1578.

32. Cheng SB, Skinner CD, Taylor J, Attiya S, Lee WE, Picelli G, Harrison DJ: Development of a multichannel microfluidic analysis system employing affinity capillary electrophoresis for immunoassay. Anal Chem 2001, 73:1472-1479.

33. Wang J, Ibanez A, Chatrathi MP: Microchip-based amperometric immunoassays using redox tracers. Electrophoresis 2002, 23:3744-3749.

34. Rossier JS, Girault HH: Enzyme linked immunosorbent assay on

- a microchip with electrochemical detection. Lab on a chip 2001, 1:153-157.

This paper shows how miniaturization can result in a dramatic decrease in time-to-result delay: an immunoassay for D-Dimer, a thrombo-embolic event marker, is completed within 5 min thanks to proper control of incubation steps within microfluidic channels.

35. Linder V, Verpoorte E, de Rooij NF, Sigrist H, Thormann W: Application of surface biopassivated disosable poly(dimethylsiloxane)/glass chips to a heterogeneous competitive human serum immunoglobulin $\mathrm{G}$ immunoassay with incorporated internal standard. Electrophoresis 2002 23:740-749.

36. Linder V, Verpoorte E, Thormann W, de Rooij NF, Sigrist M: Surface biopassivation of replicated poly(dimethylsiloxane) microfluidic channels and application to heterogeneous immunoreaction with on-chip fluorescence detection. Anal Chem 2001, 73:4181-4189.

37. Dodge A, Fluri K, Verpoorte E, de Rooij NF: Electrokinetically driven microfluidic chips with surface-modified chambers for heterogeneous immunoassays. Anal Chem 2001, 73:3400-3409.

38. Sapsford KE, Charles PT, Patterson CH, Ligler FS: Demonstration of four immunoassay formats using the array biosensor. Anal Chem 2002, 74:1061-1068.
39. Sato K, Yamanaka M, Takahashi H, Tokeshi M, Kimura H, Kitamori T: Microchip-based immunoassay system with branching multichannels for simultaneous determination of interferon- $\gamma$. Electrophoresis 2002, 23:734-739.

40. Choi JW, Oh KW, Thomas JH, Heineman WR, Halsall HB, Nevin JH, Helmicki AJ, Henderson $\mathrm{HT}$, Ahn $\mathrm{CH}$ : An integrated microfluidic biochemical detection system for protein analysis with magnetic bead-based sampling capabilities. Lab on a Chip 2002, 2:27-30.

41. Rossier JS, Gokulrangan G, Girault HH, Svojanovsky S, Wilson GS Characterization of protein adsorption and immunosorption kinetics in photoablated polymer microchannels. Langmuir 2000, 16:8489-8494.

42. Slentz BE, Penner NA, Regnier FE: Protein proteolysis and the multi-dimensional electrochromatographic separation of histidine-containing peptide fragments on a chip. J Chromatogr A 2003, 984:97-107.

43. Li JJ, LeRiche T, Tremblay TL, Wang C, Bonneil E, Harrison DJ, -. Thibault P: Application of microfluidic devices to proteomics research - identification of trace-level protein digests and affinity capture of target peptides. Mol Cell Proteomics 2002 1:157-168.

Although it could be improved, especially in terms of sensitivity and throughput, the microdevice presented in this study is a true proteomic platform, allowing SPE-CE-MS analysis of tryptic protein digests from 2D-GE spots at a rate of 12 samples per hour.

44. Lichtenberg J, de Rooij NF, Verpoorte E: Sample pretreatment on - microfabricated devices. Talanta 2002, 56:233-266.

Although not limited to protein analysis, this review provides a very comprehensive overview of microfluidic developments for sample preparation, covering SPE, liquid-liquid extraction, field-amplified stacking transient isotachophoresis, labeling issues and so on.

45. Rabilloud T: Two-dimensional gel electrophoresis in proteomics: old, old fashioned, but it still climbs up the mountains. Proteomics 2002, 2:3-10.

46. Haab BB, Dunham MJ, Brown PO: Protein microarrays for highly parallel detection and quantitation of specific proteins and antibodies in complex solutions. Genome Biol 2001, 2:RESEARCH0004.

47. Peterson DS, Rohr T, Svec F, Frechet JMJ: Dual-function microanalytical device by in situ photolithographic grafting of porous polymer monolith: integrating solid-phase extraction and enzymatic digestion for peptide mass mapping. Anal Chem 2003, 75:5328-5335. 